Note

\title{
Interdisciplinary Learning: A Strategy of Chinese Honors Education for providing depth and scale of learning
}

\author{
YE Jing-jia ${ }^{1 *}$, QIU Li-min ${ }^{1}$, TANG Xiao-wu ${ }^{1}$
}

1. Chu Kochen Honors College, Zhejiang University, China; yej001@zju.edu.cn; limin.qiu@zju.edu.cn; tangxiaowu@zju.edu.cn

* Corresponding author: yej001@zju.edu.cn

Received: 28 June 2017; Accepted: 13 September 2017; Published: 20 October 2017

Keywords: Interdisciplinary Learning, Honors Education, Chu Kochen Honors College

\begin{abstract}
Chu Kochen Honors College (CKC) offers a series of honors programs for talented and motivated students from all academic disciplines of Zhejiang University (ZJU). The Honors Programs offer both general education and interdisciplinary learning. Through the customized curriculum and interdisciplinary training, honors students will be required to push themselves academically and strive for excellence. Students enrolled in honors programs are encouraged to become independent thinkers and creative problem solvers.
\end{abstract}

\section{Introduction}

Chu Kochen Honors College (CKC) was established in 1984, named after the great scientist professor Chu Kochen (1890-1974). Chu Kochen Honors College (CKC) is one of the oldest Honors Colleges and also the most comprehensive honors college in China and a member of the C9 group. C9 is the group of 9 top universities listed into China's 985 project for nurturing first-class universities, including Peking University, Tsinghua University, Fudan University, Shanghai Jiao Tong University, Nanjing University, Zhejiang University, University Of Science And Technology Of China, Harbin Institute Of Technology and Xi' an Jiaotong University (see table 1). Professor Chu Kochen was not only a world famous expert on meteorology and geography but also a great educationist. He stressed that the purpose of a university is to bring up students 'who are fair, faithful and firm, who can take the leadership and steer a nation' when he acted as the president of Zhejiang University.

In 2005, professor Hsue-shen Tsien, known as 'The Father of Chinese missile', raised a question to the higher education in China: 'After so many years, no achievements of any of our students are comparable to that of the academic masters of Republic of China period (1912-1949). Why do we always fail in cultivating outstanding talents?' 
Table 1. Chinese C9 Collegiate Honors Colleges and Programs

\begin{tabular}{|c|c|c|c|c|c|}
\hline University Name & Program Name & $\begin{array}{c}\text { Establishe } \\
\text { d Time }\end{array}$ & $\begin{array}{l}\text { Number of } \\
\text { Honors } \\
\text { Students }\end{array}$ & $\begin{array}{l}\text { Number of } \\
\text { Students at } \\
\text { University }\end{array}$ & Proportion \\
\hline $\begin{array}{c}\text { University of Science } \\
\text { and Technology of } \\
\text { China }\end{array}$ & $\begin{array}{l}\text { School of the } \\
\text { Gifted Young }\end{array}$ & 1978 & 520 & 7400 & $7.02 \%$ \\
\hline Zhejiang University & $\begin{array}{l}\text { Chu Kochen } \\
\text { Honors College }\end{array}$ & 1984 & 1760 & 22929 & $7.68 \%$ \\
\hline $\begin{array}{l}\text { Xi'an Jiaotong } \\
\text { University }\end{array}$ & $\begin{array}{l}\text { Class for Gifted young } \\
\text { people } \\
\text { /Qian Xuesen } \\
\text { Experimental Class/ }\end{array}$ & $\begin{array}{l}1985 / \\
2007\end{array}$ & 920 & 16126 & $5.71 \%$ \\
\hline $\begin{array}{l}\text { Harbin Institute of } \\
\text { Technology }\end{array}$ & $\begin{array}{c}\text { Honors School of } \\
\text { HIT }\end{array}$ & 1993 & 480 & 16280 & $2.95 \%$ \\
\hline Nanjing University & $\begin{array}{l}\text { Kuang Yaming } \\
\text { Honors School }\end{array}$ & 1998 & 400 & 12800 & $3.13 \%$ \\
\hline Peking University & Yuanpei College & 2001 & 480 & 11368 & $4.22 \%$ \\
\hline Fudan University & Wangdao Program & 2010 & 680 & 14100 & $4.82 \%$ \\
\hline $\begin{array}{c}\text { Shanghai Jiao Tong } \\
\text { University }\end{array}$ & Zhiyuan College & 2010 & 560 & 16116 & $3.47 \%$ \\
\hline Tsinghua University & $\begin{array}{c}\text { Tsinghua Xuetang } \\
\text { Personnel Cultivating } \\
\text { Plan }\end{array}$ & 2011 & 560 & 15184 & $3.69 \%$ \\
\hline Total & & & 6360 & 132303 & $4.81 \%$ \\
\hline
\end{tabular}

Source: Ye, Qiu \& Xing, 2017

\section{Focus of the College}

As a response to the 'question of Tsien', Chu Kochen Honors College improves the honors programs to help students to develop their innovative ability and build up a solid academic background, by emphasizing on interdisciplinary study and encouraging innovation. A series of honors courses and seminar courses are offered to honors students, and multidisciplinary scholars from across the university are invited to be mentors of honors students.

The current programs of CKC include Honors Program of Science \& Engineering (mixed class), Honors Program of Liberal Arts \& Social Science, Pursuit Science Class, Badenian Class program for medicine, Composite Training Programs and so on.

\section{Programs}

For example, the Honors Program of Science \& Engineering (mixed class) was started from 1984, aiming to enhance the science foundation of engineering students and to improve the ability of science students to innovatively use practical knowledge and solve real problems. A special curriculum is designed to help students build up a solid academic background in Science, including a diverse array of honors-level core courses, departmental honors courses, interdisciplinary honors courses and leadership development. During the first two academic years, the curriculum aim is capacity training. Honors courses provide depth and breadth of study. Honors students also benefit from the customized curriculum which 
includes interdisciplinary seminars and sequenced courses on research methods and a series of interdisciplinary seminars on topics not typically offered by other departments (e.g. in CKC, every year experts are invited to interpret for honors students the research work which won the Nobel Prize). For the following two years, all students are to select their majors in any field offered at ZJU and they need to complete a research project and a thesis under the advisement of a faculty mentor. Honors students are encouraged to engage in more interdisciplinary studies. And the students can also earn honors credit by overseas study and internship experiences. Students of CKC pursue majors in all undergraduate divisions, and they are encouraged to develop the ability to understand the content, merit, and limitations of different issues in science.

A vibrant community is created among students and teachers through the social and cultural activities orchestrated by the program. To enrich college lives, CKC organizes a series of campus cultural activities. As a symbol of the special cultivating style in CKC, MIX Day is celebrated every autumn. It includes a series of exciting activities to show the students' creativity, dreams and abilities.

Since 2015, three interdisciplinary learning programs have been carried out in CKC, including Finance + Mathematics, Computer Science + Statistics, Automation + Computer Science. These programs are supported by the School of Economics, School of Mathematical Sciences, College of Computer Science and Technology, and College of Control Science and Engineering, under the coordination of the CKC. The interdisciplinary programs offer double degree / double professional training in four years for selected students and are expected to bring advantages not only to students but also mentors and the university. However, to improve the model of interdisciplinary education there are still some issues which need exploration and perfection:

1. How to recognize the students with high potential and open-minded.

2. How to provide an effective platform for communication between teachers and students involved in the interdisciplinary programs.

Each year, about 500 new students are selected for CKC. Only the top ten percent incoming freshmen and current full-time ZJU students with a minimum GPA of 4.0 may apply to join the CKC. The honors students are selected based on their high school GPA, performance in screening tests and interviews which focus on their ambition, potential traits, stress coping skills, leadership, responsiveness, independent spirit and initiative. They must maintain at least a 3.0 cumulative GPA and complete 22 credits per semester in the first two years to keep in good standing with the Honors College.

These honors students are instructed by a group of the best scholars who are full of enthusiasm for the honors programs on campus. To teach in honors or guide honors students, faculty must be distinguished in their research field and with rich teaching experiences. To emphasize interdisciplinary learning, students are encouraged to form interdisciplinary teams to tackle projects of their interests under the guidance of an interdisciplinary team of mentors.

Up to date, there are about eight thousand honors alumni of CKC worldwide. Some of them have already made remarkable contributions in their own fields. One of the honors alumni, Professor Wu Zhaohui, is now the president of Zhejiang University and the dean of CKC. Facing the complicated and rapidly changing environments in higher education, some research projects of higher education are also carried out in CKC to provide clues of what will 
be the best for the development of honors students. CKC is also looking forward to have more inspiration to improve the quality of education through learning from experience of honors education in the United States (Jones, 2016; Kampf, Chasek \& Falconer, 2016) and Europe (Wolfensberger, 2015; Van Eijl, Moesker \& Eyckmans, 2017).

\section{References}

For more information about CKC, please visit the website: http://ckc.zju.edu.cn/english/.

Jones, B.M. (2016). Toward a Science of Honors Education. Journal of the National Collegiate Honors Council 17(1), 307-333.

http://digitalcommons.unl.edu/cgi/viewcontent.cgi?article=1516\&context=nchcjournal

Kampfe, J.A., Chasek, C.L., Falconer, J. (2016). An Examination of Student Engagement and Retention in an Honors Program. Journal of the National Collegiate Honors Council 17(1), pp. 219-235.

http://digitalcommons.unl.edu/cgi/viewcontent.cgi?article=1517\&context=nchcjournal

Wolfensberger, M.V.C. (2015). Talent Development in European Higher Education. Honors programs in the Benelux, Nordic and German-speaking countries. Heidelberg, New York, Dordrecht \& London: Springer Open. http://doi.org/10.1007/978-3-319-12919-8

Van Eijl, P., Moesker, H., Eyckmans, M. (2017). Different views on assuring the quality of honours programmes. Journal of the European Honors Council 1(1), 7, pp. 1-12. Available online: https://www.honorscouncil.eu/jehc/JEHC20170107VanEij|EtAl.pdf

Ye, J., Qiu, L., Xing, Y. (2017). The Study of Characteristics and Development of Honors Education of China with An International Perspective. Education Research of Zhejiang University 2017(1), 1-11. In Chinese (full text):

http://www.rcstep.zju.edu.cn/jozer/redir.php?catalog id=5254\&object id=5265 (can be requested from corresponding author)

\section{Funding information}

The research on which this article has been based was supported by the following funds:

1. Department of Higher Education, Ministry of Education of People's Republic of China. A Study on the Evaluation Mechanism of Teaching Quality of Top - notch Students (No. 20170502)

2. Institute of Higher Education, Zhejiang University. A Study on the Core Elements of Cultivating Top Innovative Students in Zhejiang University (No. G1519) 